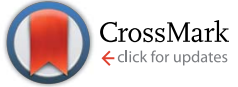

Cite this: RSC Adv., 2017, 7, 3540

Received 26th October 2016 Accepted 26th November 2016

DOI: 10.1039/c6ra25883b

www.rsc.org/advances

\title{
Assembly of 3D flower-like NiO hierarchical architectures by 2D nanosheets: synthesis and their sensing properties to formaldehyde $\uparrow$
}

\author{
Xiaoguang San, ${ }^{a}$ Guodong Zhao, ${ }^{a}$ Guosheng Wang, ${ }^{a}$ Yanbai Shen, ${ }^{b}$ Dan Meng, ${ }^{\text {*a }}$ \\ Yajing Zhang ${ }^{a}$ and Fanli Meng ${ }^{\star c}$
}

\begin{abstract}
Flower-like $\mathrm{NiO}$ hierarchical architectures were synthesized by a solvothermal process without using any other surfactant. Absolute ethanol and distilled water were adopted as solvent, and nickel nitrate hexahydrate was employed as the nickel source. The morphology and crystal structure were mainly investigated. Through annealing the as-obtained products, flower-like $\mathrm{NiO}$ hierarchical architectures with a cubic structure were synthesized, which were assembled by a number of thin nanosheets with a thickness of about $30 \mathrm{~nm}$. The formaldehyde gas sensing measurements showed that well-defined $\mathrm{NiO}$ flower-like structures with large surface area exhibited higher responses compared with microsheets/nanosheets at a relatively lower operating temperature of $200{ }^{\circ} \mathrm{C}$. Moreover, a reversible and fast response to formaldehyde gas at various gas concentrations, good selectivity and stability were obtained. The results indicated that the flower-like $\mathrm{NiO}$ hierarchical architectures are promising materials for gas sensors.
\end{abstract}

\section{Introduction}

Semiconductor oxide nanomaterials are of great interest due to their unique optical, electrical and magnetic properties and their wide applications in various areas of science and technology. ${ }^{1-4}$ In particular, with the development of nano-science and nano-technology, three-dimensional (3D) complexes and hierarchical architectures in nano-scales or micro-scales assembled by nano-sized building blocks (particles, rods, sheets, etc.) have been the focus of considerable interest in recent years. ${ }^{5}$ These kinds of structures possess low density, large surface area, high structure stability, and outstanding transportation properties in comparison with their lowdimensional-counterparts, and therefore represent a very promising design option for exploring novel properties and superior device performances. ${ }^{6-8}$ So far, a variety of semiconductor oxides, such as $\mathrm{ZnO}, \mathrm{WO}_{3}$ and $\mathrm{Co}_{3} \mathrm{O}_{4}$, with hierarchical architectures have been successfully synthesized by different methodologies and which exhibit potential

${ }^{a}$ College of Chemical Engineering, Shenyang University of Chemical Technology, Shenyang 110142, China. E-mail: mengdan0610@hotmail.com; Fax: +86 248938 6342; Tel: +862489386342

${ }^{b}$ College of Resources and Civil Engineering, Northeastern University, Shenyang 110819, China

${ }^{`}$ Research Center for Biomimetic Functional Materials and Sensing Devices, Institute of Intelligent Machines, Chinese Academy of Sciences, Hefei 230031, China. E-mail: flmeng@iim.ac.cn

$\dagger$ Electronic supplementary information (ESI) available. See DOI: $10.1039 / \mathrm{c} 6 \mathrm{ra} 25883 \mathrm{~b}$ application as solar cell, gas sensor, lithium-ion batteries, etc., due to their unique geometric configuration. ${ }^{9-11}$ For example, Ko et al. ${ }^{9}$ reported that tree-like hierarchical $\mathrm{ZnO}$ nanostructures assembled by $\mathrm{ZnO}$ nanowires demonstrated potential application in dye-sensitized solar cell. Huang et al. ${ }^{10}$ reported that $\mathrm{WO}_{3}$ flower-like hierarchical structures exhibited a good response and reversibility to organic gases.

Up to now, the controlling fabrication of ordered 3D hierarchical architectures and controlling their morphology at the microscopic level have been of tremendous scientific and technological interest, as the physical and chemical properties of hierarchical architectures are largely dependent on their size and morphology. ${ }^{12}$ Different synthetic routes have been explored to prepare 3D hierarchical architectures, among which, the hydrothermal/solvothermal process, as a valid method, has been widely used. ${ }^{13,14}$ However, some surfactant or assistant agent is commonly used to control the morphology and structure, which may introduce impurities and affect the properties adversely. Therefore, it is of great importance to synthesize 3D hierarchical architectures with surfactant or assistant agent free, solution based, morphology controlled approaches and investigate their application performance currently.

Nickel oxide (NiO), as a transparent semiconductor oxide, has been extensively investigated owing to its abundant applications in many fields, especially for energy storage devices. ${ }^{15-22}$ Furthermore, NiO with stable wide band gap energy also show promise for gas-sensing applications. ${ }^{23,24}$ Gas sensors based on NiO with various morphologies such as nanoparticles, 
nanowires and nanosheets have been widely studied, which showed high response, good stability, simplicity of fabrication, etc. $^{25-27}$ However, the working temperature of $\mathrm{NiO}$ sensor is relatively higher than $200{ }^{\circ} \mathrm{C}$. Hence, the NiO sensor with high response and low operating temperature is still demanded for further application. From the viewpoint of gas sensor, hierarchical architectures can provide large surface area with less agglomeration to ensure abundant adsorption sites for gas adsorption and desorption, which can significantly improve sensing performance. ${ }^{8}$ Recently, a variety of metal oxide semiconductors such as $\mathrm{In}_{2} \mathrm{O}_{3},{ }^{28} \mathrm{WO}_{3},{ }^{10,29} \mathrm{ZnO},{ }^{30}$ and $\mathrm{SnO}_{2}$ (ref. 31) with hierarchical structures have been synthesized and showed good sensing properties to the detected gases. Although the application of NiO hierarchical architectures in gas sensors has been reported, it has not been well studied. Furthermore, it noted that the a few models for a gas response of p-type semiconducting metal oxide have been recently suggested, and thus the systematic investigation of its sensing properties is necessary to understand gas sensing mechanisms. In addition, a study on p-type oxides is very significant in that their use makes novel sensors such as a $\mathrm{p}-\mathrm{n}$ diode and tandem devices possible.

Therefore, in this study, we report on the synthesis of flowerlike NiO hierarchical architectures composed of thin nanosheets through solvothermal process in ethanol/water system without using any surfactant. The morphologies and structures as well as their formaldehyde gas sensing properties were investigated. The results showed that the sensor fabricated from flower-like NiO hierarchical architectures exhibited good sensing properties at relatively lower operating temperature of $200{ }^{\circ} \mathrm{C}$, demonstrating potential of these unique hierarchical architectures for gas sensor application.

\section{Experimental}

NiO was synthesized by a simple solvothermal route in ethanol/ water system without using any other surfactant. Nickel nitrate hexahydrate $\left(\mathrm{Ni}\left(\mathrm{NO}_{3}\right)_{2} \cdot 6 \mathrm{H}_{2} \mathrm{O}\right)$ was employed as the nickel source. In a typical procedure (Fig. 1(a)), $2 \mathrm{mmol}$ of $\mathrm{Ni}\left(\mathrm{NO}_{3}\right)_{2} \cdot 6 \mathrm{H}_{2} \mathrm{O}$ was dissolved in $40 \mathrm{ml}$ solvent under magnetic stirring at room temperature to get a clear solution. Here, the solvent is mixed solution of ethanol and distilled water with a calculated volume ratio, that is, ethanol/water volume ratio is $40 / 0$ (pure absolute ethanol), 30/10, 20/20, 10/30, 0/40 (pure water). Then the solution was transferred into a $50 \mathrm{ml}$ Teflon-lined stainless autoclave, which was sealed and maintained at $180{ }^{\circ} \mathrm{C}$ for $12 \mathrm{~h}$. After that, the autoclave was cooled to room temperature, and a green precipitate was obtained. The precipitate was separate by centrifugation, followed by repeated washing using distilled water and ethanol, and then dried in vacuum at $60^{\circ} \mathrm{C}$ for $4 \mathrm{~h}$. In order to investigate the development of NiO crystals, the reactions were also conducted at different reaction times from $1 \mathrm{~h}$ to $24 \mathrm{~h}$ at $180{ }^{\circ} \mathrm{C}$, all using mixed solution of ethanol/water (30/10) as the solvent. Finally, the grey black product was obtained through annealing at $400{ }^{\circ} \mathrm{C}$ for $4 \mathrm{~h}$ in air.

The obtained products were characterized using an X-ray diffractometer (XRD, Shimadzu XRD-6100), a field emission scanning electron microscope (FESEM, ZEISS Ultra Plus), a transmission electron microscopy (TEM, JEOL EM002B), an Xray photoelectron spectra (XPS, JEOL JPS9010MC), and a Brunauer-Emmett-Teller (BET) nitrogen adsorption-desorption (Tristar II 3020M). The thermogravimetry and differential thermal analysis (TG-DTA) was also carried out using a Shimadzu, DTG-60H apparatus. The sample was heated from room temperature to $800{ }^{\circ} \mathrm{C}$ at a rate of $10{ }^{\circ} \mathrm{C} \mathrm{min}^{-1}$ in air.

To fabricate a gas sensor, the $\mathrm{NiO}$ products were dispersed in ethanol solvent and directly poured a few drops of productsuspended ethanol onto alumina substrates equipped with a pair of interdigitated Au electrodes and four Pt wires (Fig. 1(b)). The size of the sensing element was $1 \times 1.5 \mathrm{~mm}^{2}$. Before measuring gas-sensing properties, the sensors were aged in ambient air for $24 \mathrm{~h}$ at $400{ }^{\circ} \mathrm{C}$ to improve their stability and repeatability. The gas-sensing measurements were performed on a static system (WS-30A, Hanwei Electronics Co. Ltd., Henan Province, China) with the constant loop voltage of 5 V. Fig. 1(c) shows the schematic diagram of measurement electric circuit. The response value of the sensor is defined as the ratio of the electrical resistance in the mixture of test gas and air $\left(R_{\mathrm{g}}\right)$ to the electrical resistance in air $\left(R_{\mathrm{a}}\right)$, which is given by the equation: $S=R_{\mathrm{g}} / R_{\mathrm{a}}$.
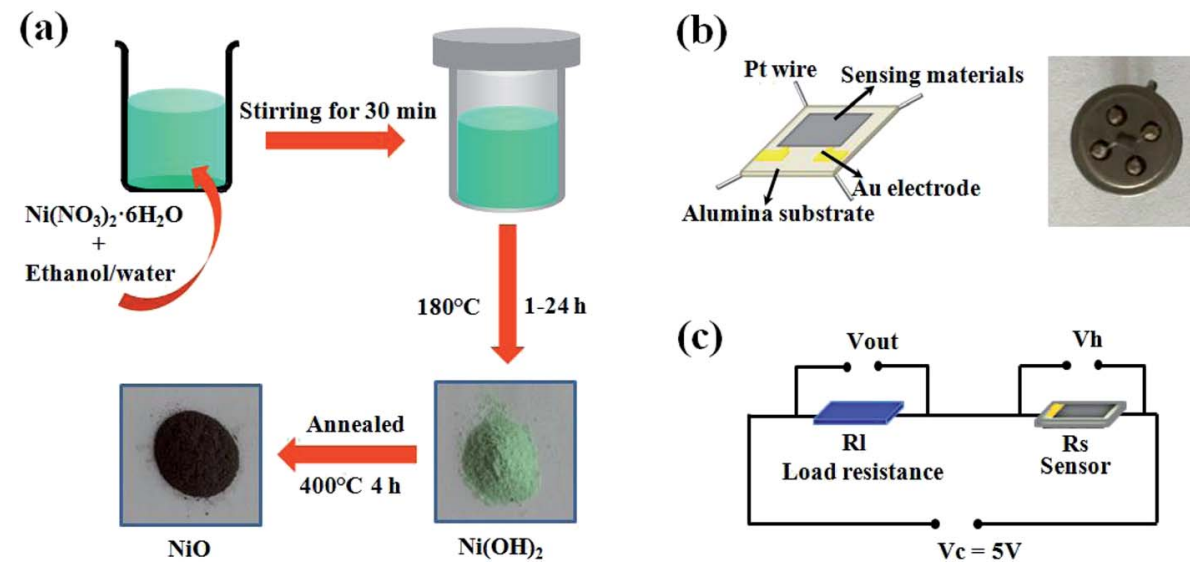

Fig. 1 (a) Schematic illustration of the synthesis process of NiO product. (b) Schematic diagram and photograph of the gas sensor. (c) Schematic diagram of measurement electric circuit. 


\section{Results and discussion}

\section{Characterizations of precursor}

The XRD pattern and FESEM images of the as-obtained products synthesized at ethanol/water volume ratio of 30/10 are shown in Fig. 2. From XRD pattern (Fig. 2(a)), seven main peaks corresponding to the crystallographic planes of (001), (002), (110), (111), (200), (103), and (300) are clearly observed, which characterize a hexagonal $\alpha-\mathrm{Ni}(\mathrm{OH})_{2}$ (JCPDS card no. 22-0444). No impurity peaks are found in the XRD pattern, suggesting a high purity of the as-obtained $\alpha-\mathrm{Ni}(\mathrm{OH})_{2}$. The morphology of the product was observed by FESEM. The low magnification image (Fig. 2(b)) indicates that the products composed of the flower-like structures with a diameter ranging from 6 to $10 \mu \mathrm{m}$. Further observation (Fig. 2(c) and (d)) shows these flower-like structures are constructed by the intersectional nanosheets with a uniform thickness of about $30 \mathrm{~nm}$.

The thermal stability of the as-obtained products synthesized at ethanol/water volume ratio of 30/10 was analyzed by TG-DTA, as shown in Fig. S1. $\dagger$ The TG curve of the precursor shows that $\mathrm{Ni}(\mathrm{OH})_{2}$ started to decompose (accompanied with weight loss) at about $285{ }^{\circ} \mathrm{C}$. The major weight loss could be observed in the range of $300-345^{\circ} \mathrm{C}$. A strong endothermic peak with a maximum was located at $330{ }^{\circ} \mathrm{C}$ in the DTA curve, which fits well with that of weight loss in the TG curve, corresponding to endothermic behavior during the decomposition of $\mathrm{Ni}(\mathrm{OH})_{2}$ to NiO. On the basis of the TG-DTA results, the as-prepared $\mathrm{Ni}(\mathrm{OH})_{2}$ crystals can be converted into $\mathrm{NiO}$ after being annealed at $400{ }^{\circ} \mathrm{C}$ for $4 \mathrm{~h}$.

\section{Characterizations of flower-like NiO hierarchical architectures}

The microstructure and morphology of the annealed products synthesized at ethanol/water volume ratio of 30/10 are investigated by XRD, FESEM, TEM, high-resolution TEM (HRTEM) and selected area electron diffraction (SAED) with the results shown in Fig. 3. From XRD pattern (Fig. 3(a)), it is found that after annealing at $400{ }^{\circ} \mathrm{C}$ for $4 \mathrm{~h}$, five main peaks corresponding to the crystallographic planes of (111), (200), (220), (311), and (222) are observed, which characterize a cubic structure of the NiO, in accordance with standard JCPDS cards 73-1523. The strong and sharp diffraction peaks indicate the good crystallinity of the products. No diffraction peaks of $\alpha-\mathrm{Ni}(\mathrm{OH})_{2}$ are found, indicating that the $\alpha-\mathrm{Ni}(\mathrm{OH})_{2}$ was completely transformed to $\mathrm{NiO}$ at $400{ }^{\circ} \mathrm{C}$ for $4 \mathrm{~h}$. From FESEM images (Fig. 3(b)-(d)), it is found that after annealing at $400{ }^{\circ} \mathrm{C}$ for $4 \mathrm{~h}$, the overall morphologies of the intersectional nanosheets composed of flower-like structures are mostly preserved without significant changes, which inherits the interesting morphology of the solvothermally prepared precursor. The corresponding TEM image shown in Fig. 3(e) revealed that flower-like structures are composed of $\mathrm{NiO}$ thin nanosheets, and some of them overlap with each other. Further observation shown in Fig. 3(f) demonstrates that a NiO nanosheet is full of numerous pores, which should be attributed to the removal of water and the release of gas molecules during the pyrolysis of the precursor. This kind of structures with many petals, pores and intervals, provide excellent channels and surface accessibility for the target gas transporting and reacting with the sensing materials, indicating a very good candidate for gas sensor. A HRTEM image of these nanosheets and the corresponding SAED pattern are shown in Fig. $3(\mathrm{~g})$ and $(\mathrm{h})$, from which single-crystalline structure can be observed. The lattice fringe spacing is $0.21 \mathrm{~nm}$, which is close to the (200) crystal planes of standard cubic phase of NiO.

In order to further describe the chemical composition and chemical bonding state of the NiO product, XPS characterization on the annealed product synthesized at ethanol/water volume ratio of 30/10 was carried out (Fig. 4). Wide scanning spectrum in Fig. 4(a) indicates that the $\mathrm{Ni}$, O, and $\mathrm{C}$ are present in the product and no other impurities are found. Elements
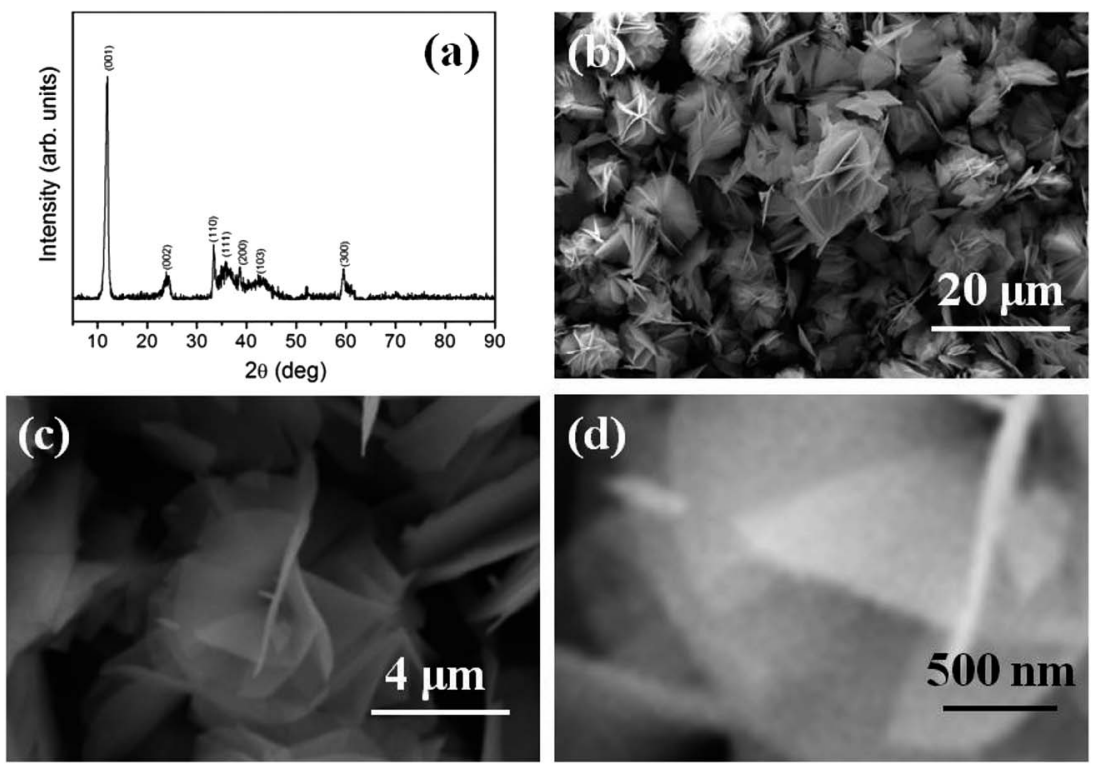

Fig. 2 (a) XRD pattern and (b-d) FESEM images of the as-obtained product synthesized at ethanol/water volume ratio of 30/10. 

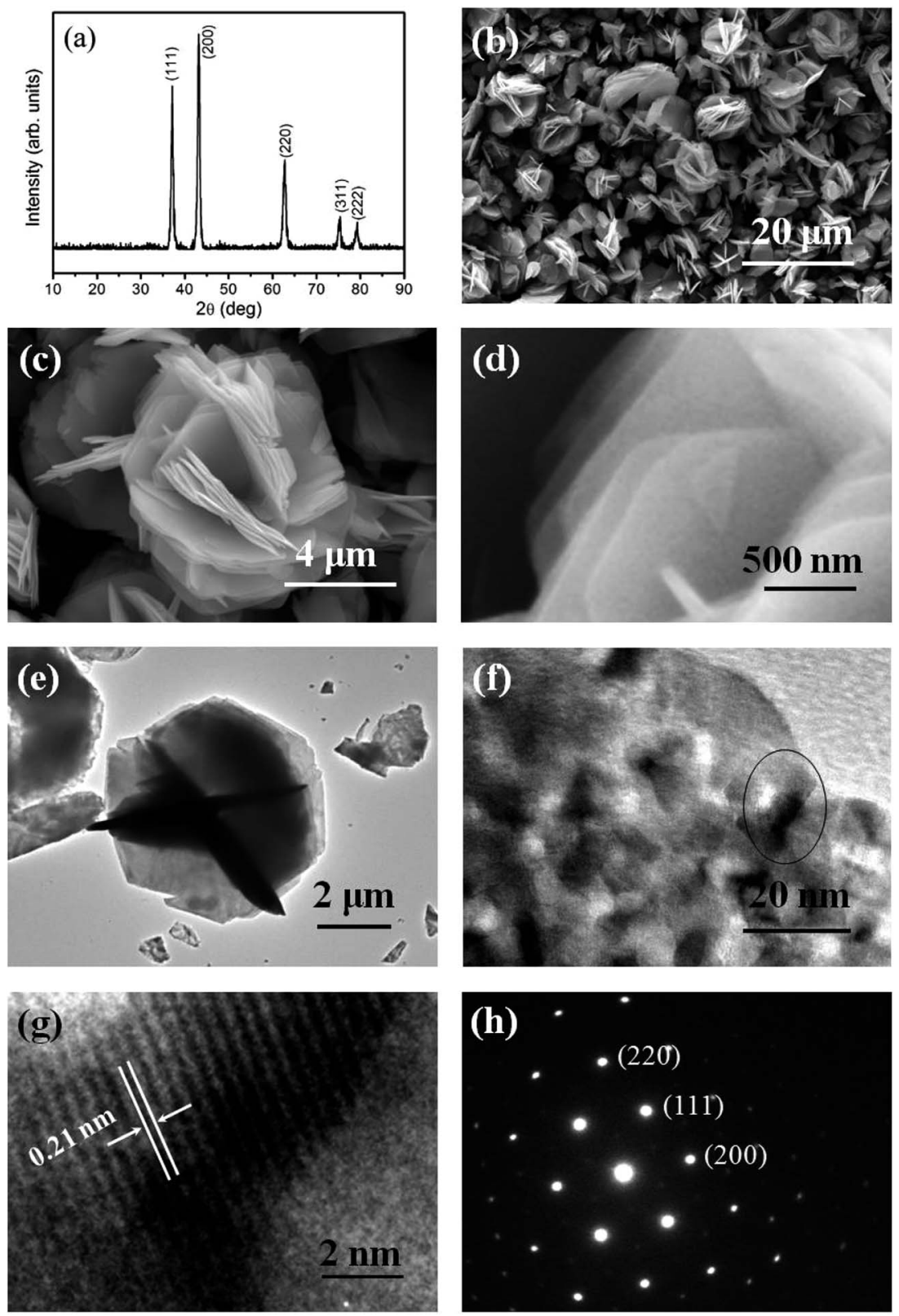

Fig. 3 (a) XRD pattern, (b-d) FESEM images, (e) TEM image, and (f) HRTEM image of the annealed product synthesized at ethanol/water volume ratio of 30/10. (g) HRTEM image and (h) SAED pattern of circle region in (f).

$\mathrm{Ni}$ and $\mathrm{O}$ belong to the $\mathrm{NiO}$ product and $\mathrm{C}$ may be attributed to the sample handling and exposure to the atmosphere prior to XPS measurements. Narrow scan XPS spectra of Ni 2p and O 1s are shown in Fig. 4(b) and (c). The Ni 2p spectrum consists of two regions assigned to the Ni $2 \mathrm{p}_{3 / 2}(850-865 \mathrm{eV})$ and $\mathrm{Ni} 2 \mathrm{p}_{1 / 2}$ (870-885 eV) spin-orbit levels. The $\mathrm{O} 1 \mathrm{~s}$ spectrum is composed of a main peak at $529.2 \mathrm{eV}$ with a shoulder at $530.9 \mathrm{eV}$. The above observation demonstrates that the product is close to the chemical stoichiometry of NiO. ${ }^{32,33}$

The nitrogen adsorption-desorption measurement isotherm and pore size distribution as the inset of the annealed product synthesized at ethanol/water volume ratio of 30/10 are shown in Fig. S2. $\dagger$ According to the IUPAC classification, this nitrogen adsorption-desorption isotherm exhibits type IV form with a type $\mathrm{H} 3$ hysteresis loop. The type $\mathrm{H} 3$ loop at the relative pressure $\left(P / P_{0}\right)$ range of $0.8-1.0$ should be ascribed to the existence of large amount of mesopores and macropores in the product. The pore size distribution curve is calculated from desorption branch of a nitrogen isotherm by the $\mathrm{BJH}$ method using the Halsey equation, which is in the long range of 2$110 \mathrm{~nm}$. The BET surface areas are 22.56 and $21.23 \mathrm{~m}^{2} \mathrm{~g}^{-1}$ for the products synthesized at ethanol/water ratio of $30 / 10$ and pure ethanol, while they are 5.82 and $4.26 \mathrm{~m}^{2} \mathrm{~g}^{-1}$ for the products synthesized at ethanol/water volume ratio of 20/20 and 10/30.

The effect of volume ratio of ethanol/water on the morphology was investigated. FESEM images of the annealed 

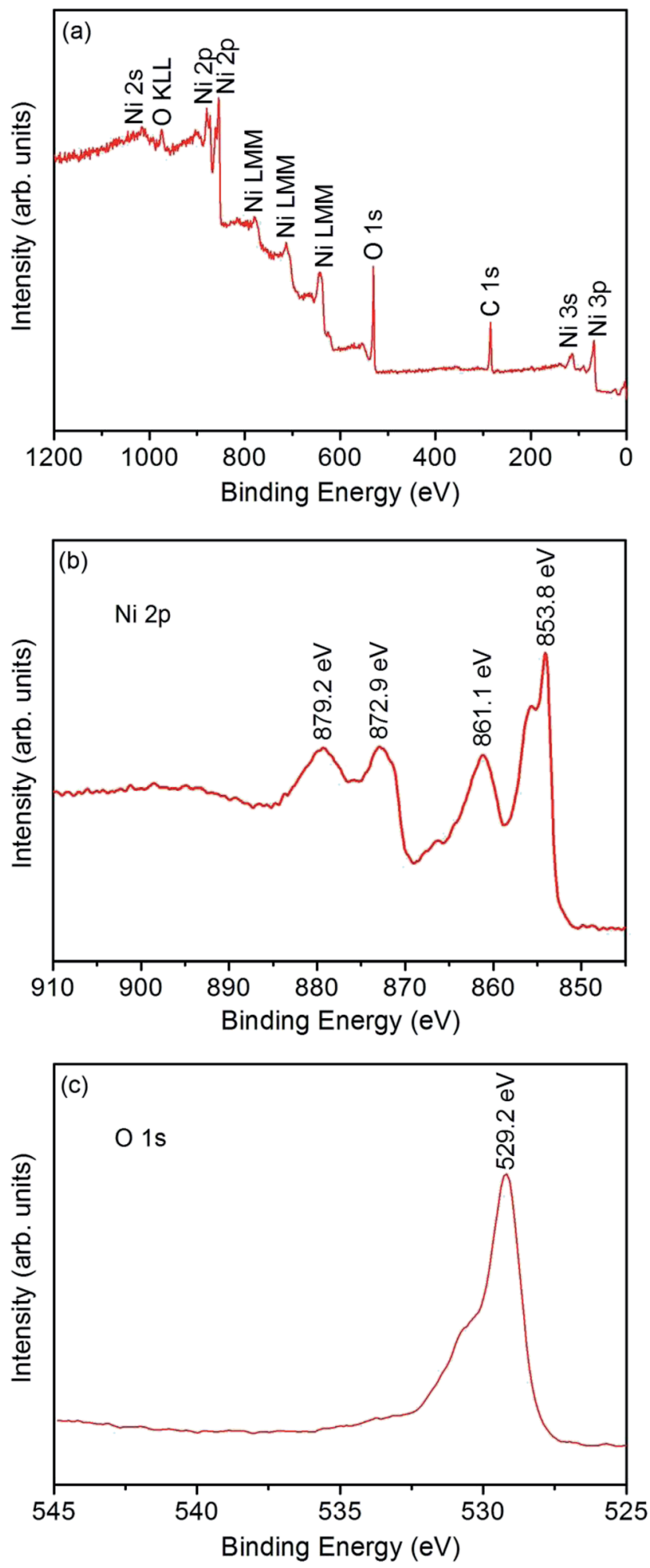

Fig. 4 XPS spectrum for the annealed product synthesized at ethanol/ water volume ratio of 30/10: (a) wide scan spectrum, (b) Ni 2p spectra, and (c) $\bigcirc$ 1s spectra.

products synthesized at $180{ }^{\circ} \mathrm{C}$ for $12 \mathrm{~h}$ with different volume ratios of ethanol/water are shown in Fig. S3. $\dagger$ No product was obtained when pure water was used as solvent. When ethanol/ water ratio was $10 / 30$, dispersed rhombohedral microsheets/ nanosheets were obtained, as shown in Fig. S3(a). $\dagger$ Some nanosheets were also obtained in the product, and some of them overlap each other to form interconnected congregates. When the ethanol/water ratio was adjusted to 20/20, microsheets/nanosheets were obtained, as shown in Fig. S3(b). $\uparrow$ Some of aggregated nanosheets show the flower-like structures. As ethanol/water ratio was further increased to 30/ 10, the flower-like structures consisted of nanosheets are clearly observed, as shown in Fig. S3(c)† and 3(b)-(d). When pure ethanol was used as solvent, as presented in Fig. S3(d), $\dagger$ the products remain the flower-like structures. While the size of flower-like structures decreased. The building blocks become to thinner nanosheets and densely pack with each other. Some nanometer-sized fragments and microsheets were also obtained, and some of them aggregated with each other. The experiment results indicate that the amount of ethanol has an important influence on the morphology of the products. Ethanol and water with different polarities and saturated vapor pressures affect the morphology of products synthesized under solvothermal treatment by adjusting the solubility of the precursor in the particular solvent, initial nucleation, agglomeration, and preferred orientation of the crystals. ${ }^{34,35}$

\section{Formation mechanism of flower-like NiO hierarchical architectures}

To investigate the formation process of the precursor, the morphological transformation of the as-obtained products synthesized at ethanol/water ratio of 30/10 for different reaction times was observed by FESEM, as shown in Fig. 5(a)-(d). No precipitation is obtained when the reaction time is less than $3 \mathrm{~h}$. When the reaction time extended to $4 \mathrm{~h}$, many irregular microsheets/nanosheets were obtained, as shown in Fig. 5(a). When the reaction time increased to $8 \mathrm{~h}$, as shown in Fig. 5(b), many aggregations with flower-like structures were obtained, which are assembled by nanosheets. When the reaction time further increased to $12 \mathrm{~h}$, the perfect flower-like structures consisted of abundant thin nanosheets were obtained (Fig. 5(c) and 2(b)-(d)). The products remained the flower-like structures at $24 \mathrm{~h}$, while some microsized structures were obtained (Fig. 5(d)). Such results reveal that the reaction time is the main factor to form nanosheets based NiO flower-like structures.

On the basis of above experimental results, we propose a possible formation mechanism for flower-like structures assembled by nanosheets, as shown in Fig. 5(e). The growth of $\mathrm{Ni}(\mathrm{OH})_{2}$ crystals is controlled by nucleation and growth processes. Firstly, primary $\mathrm{Ni}(\mathrm{OH})_{2}$ nanocrystalline nuclei were formed in the hydrolysis process of $\mathrm{Ni}\left(\mathrm{NO}_{3}\right)_{2}$ and then forming into crystals gradually. These crystals subsequently grow to thin nanosheets. As the reaction time increases, the reaction rate slows down due to the decrease of the concentration of nickel ions, which is not enough for the growth of the initial nanosheets in the circumference. Furthermore, from the thermodynamics point of view, the surface energy of an individual nanosheet is quite high with two main exposed planes, and thus they tend to aggregate perpendicularly to the surface planes to decrease the surface energy by reducing exposed areas. ${ }^{12,36}$ 

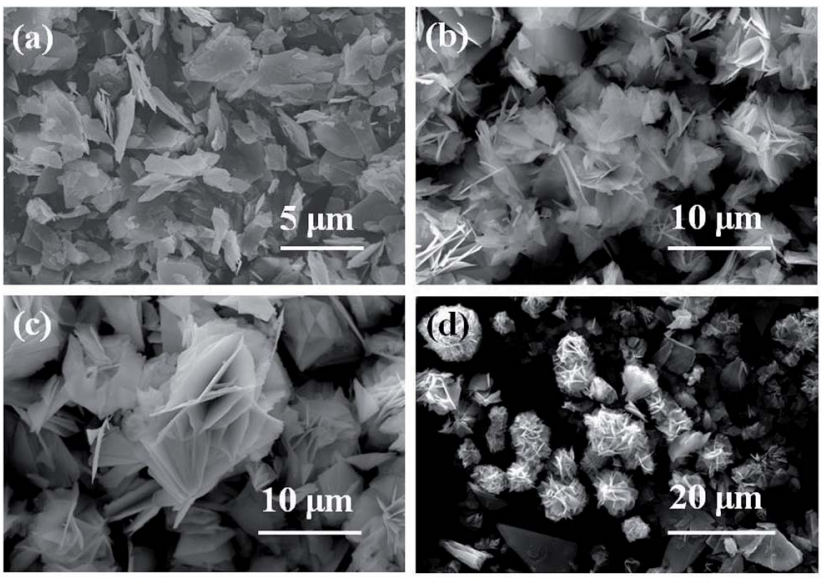

(e)
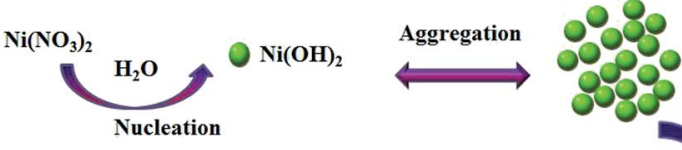

Aggregation and growth
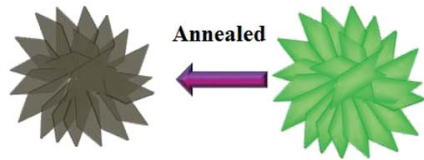

Self-assembly
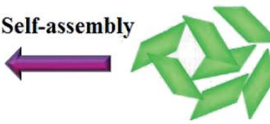

Fig. 5 (a-d) FESEM images of the as-obtained products synthesized at ethanol/water ratio of 30/10 for different times: (a) $4 \mathrm{~h}$, (b) $8 \mathrm{~h}$, (c) $12 \mathrm{~h}$, and (d) $24 \mathrm{~h}$. (e) Schematic illustration of the formation process of $\mathrm{NiO}$ hierarchical flower-like structures.

Therefore, in the aggregation and growth step, the thin nanosheets gradually self-oriented and assembled to flower-like hierarchical $\mathrm{Ni}(\mathrm{OH})_{2}$ structures under external conditions, such as electrostatic and dipolar fields associated with hydrogen bonds, and van der Waals forces. ${ }^{37,38}$ The similar evolution mechanism of flower-like structures has been reported in ref. 39 and 40. After the subsequent annealing process, the intermediate $\mathrm{Ni}(\mathrm{OH})_{2}$ lost $\mathrm{H}_{2} \mathrm{O}$ molecules and was transformed into $\mathrm{NiO}$ completely and the precursor $\mathrm{Ni}(\mathrm{OH})_{2}$ flower-like structures retained to yield NiO flower-like structures.

\section{Sensing properties of formaldehyde}

The responses of the sensor made of $\mathrm{NiO}$ with different morphology upon exposure to $100 \mathrm{ppm}$ formaldehyde gas at the operating temperatures ranging within $50-350{ }^{\circ} \mathrm{C}$ are shown in Fig. 6. For each sensor, it has an optimal temperature, at which the sensor exhibit the highest response to formaldehyde gas. The highest responses for the flower-like structures synthesize at ethanol/water volume ratio of 30/10 and pure ethanol are estimated to be 3.5 and 3.4 , respectively, at $200{ }^{\circ} \mathrm{C}$, while its are estimated to be 1.6 and 1.3 at $250{ }^{\circ} \mathrm{C}$ for the microsheets/nanosheets synthesize at ethanol/water ratio of 20 / 20 and 10/30, respectively. It is also found that the sensor made of the well-defined flower-like structures exhibits the higher response than the sensor made of the microsheets/nanosheets at almost all the operating temperatures. That is attributed to

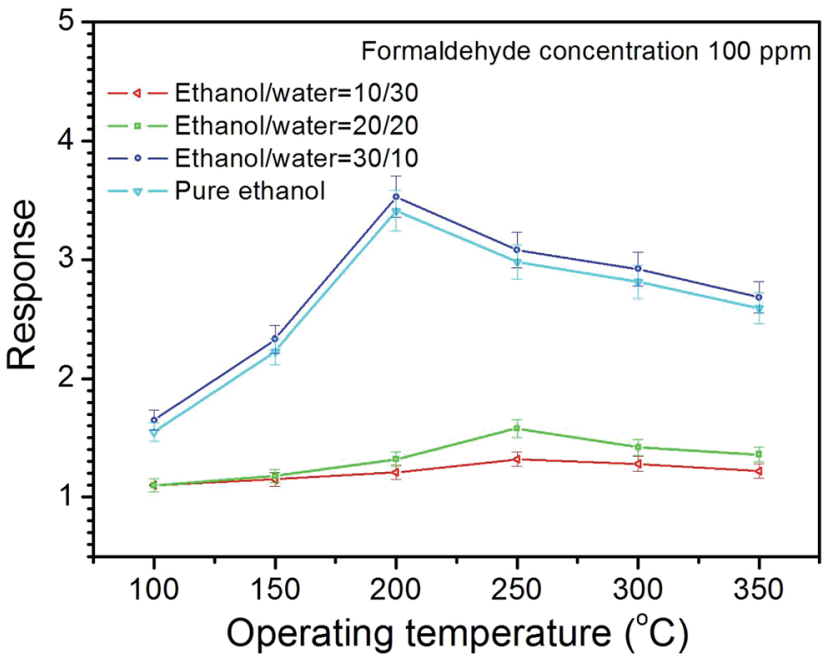

Fig. 6 Temporal responses of the sensors made of the annealed products synthesized at different ethanol/water volume ratio upon exposure to $100 \mathrm{ppm}$ formaldehyde gas at different operating temperatures.

the flower-like structures with large surface areas associated with great surface activity, which is likely to increase the gas response and decrease the operating temperature. The similar results have been also reported in the previous references, ${ }^{\mathbf{4 1 , 4 2}}$ indicating that the unique flower-like hierarchical structures with many petals, pores and intervals are very good candidate for gas sensor.

Fig. 7(a)-(d) shows the temporal responses of the sensor upon exposure to different formaldehyde concentrations $(10-500 \mathrm{ppm})$ at $200{ }^{\circ} \mathrm{C}$. It is found that all sensors exhibit good response/recovery characteristics to formaldehyde gas pulses with different concentrations, indicating excellent reversibility and stability of the sensor. It is also found that the sensor based on flower-like structures exhibits quicker response and recovery characteristics compared with the one based on microsheets/ nanosheets, indicating the good response and recover performance of flower-like structures (Fig. 7(e)). Here, the response time and recovery time are defined as the time for $90 \%$ of the total resistance increase and the time for $90 \%$ recovery of the resistance change, respectively. From Fig. 7(f), it is found that the response increases as formaldehyde concentration increases for all sensors. Furthermore, the sensor made of flower-like structures shows the higher responses than the microsheet/nanosheet sensor at all formaldehyde concentrations. Such results suggest that the sensors based on flower-like structures exhibits quicker response and recover characteristics, and higher response compared with that based on microsheets/nanosheets, indicating the good sensing performance of flower-like structures.

Selectivity is an important parameter for gas sensor. Fig. 8(a) shows the cross-sensitivities of the sensor made of NiO flowerlike structures synthesized at ethanol/water volume ratio of $30 / 10$ to $100 \mathrm{ppm}$ of different volatile organic compound gases at $200{ }^{\circ} \mathrm{C}$. The result shows that the sensor exhibits the largest responses to formaldehyde. Stability is another important 

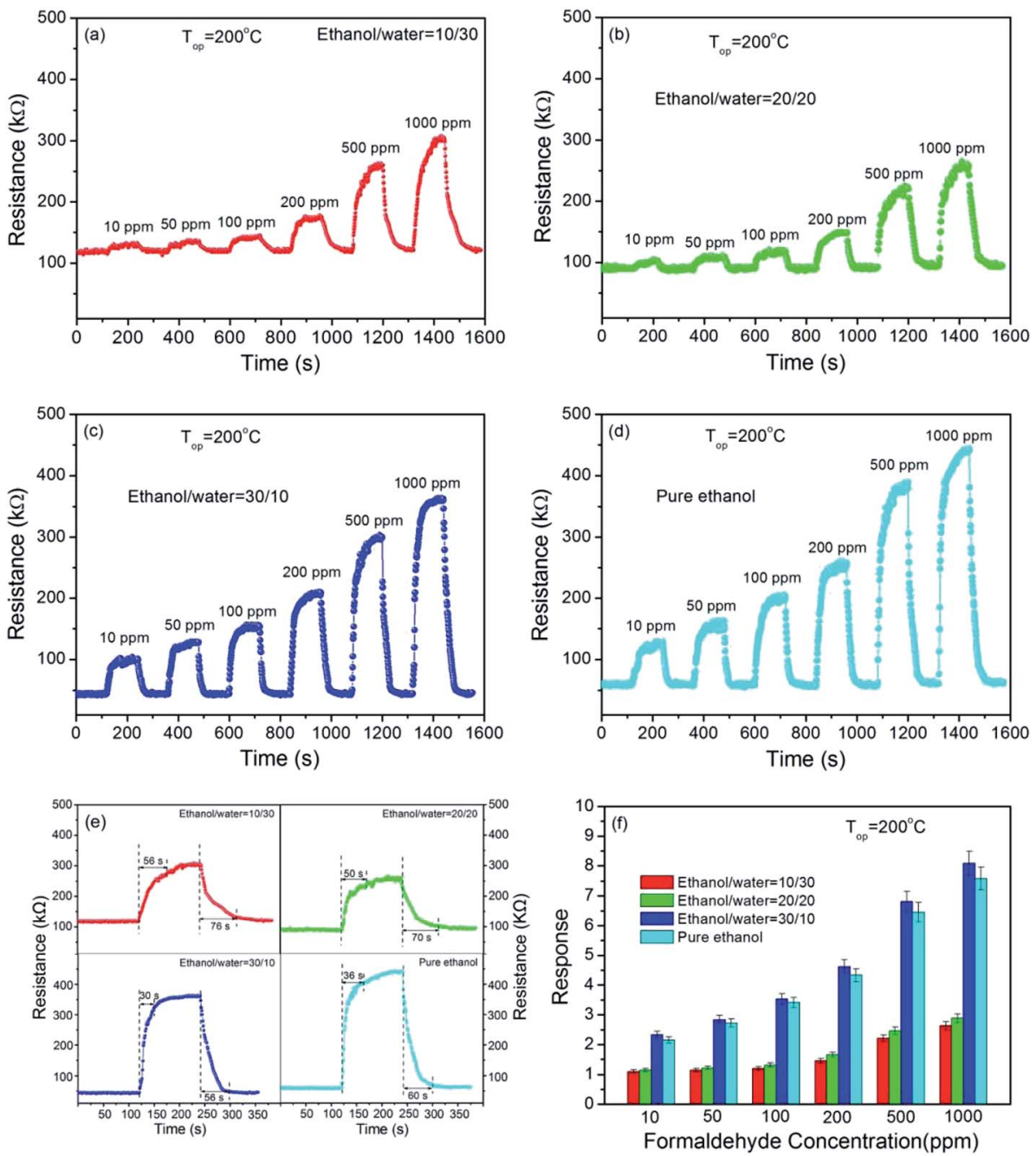

Fig. 7 (a-d) Temporal responses upon exposure to 10-1000 ppm formaldehyde gas at $200{ }^{\circ} \mathrm{C}$ : (a) ethanol/water $=10 / 30$ (microsheets/ nanosheets), (b) ethanol/water =20/20 (microsheets/nanosheets), (c) ethanol/water $=30 / 10$ (flower-like structures), and (d) ethanol/water $=$ $40 / 0$ (flower-like structures). (e) The response time and recovery time upon exposure to $1000 \mathrm{ppm}$ formaldehyde gas at $200{ }^{\circ} \mathrm{C}$. (f) The relationship between the response and formaldehyde concentrations at $200^{\circ} \mathrm{C}$. Here, the sensors were made of the annealed products synthesized at different ethanol/water volume ratio.

parameter for gas sensor. Fig. 8(b) shows the stability of the sensor made of NiO flower-like structures synthesize at ethanol/ water volume ratio of $30 / 10$ to different concentrations of formaldehyde at $200{ }^{\circ} \mathrm{C}$. The results show that the response decreased only a little after 30 days for all concentrations, implying its good stability.

To clarify sensing performance of NiO sensors, the temperature dependence of the resistances in air and that in air including formaldehyde gas are shown in Fig. 9. The resistances in air and that in air including formaldehyde gas are indicated by closed symbols and open symbols, respectively. It is found that the resistance values of both two sensors depend on temperature in air, and these values rapidly decrease at temperatures below $200{ }^{\circ} \mathrm{C}$, resulting to be steady at high temperatures. Moreover, the resistance of $\mathrm{NiO}$ sensor made of flower-like structures is lower than that of $\mathrm{NiO}$ sensor made of microsheets/nanosheets in air at all temperatures. On the other hand, the resistances of both two sensors tested in air including formaldehyde are higher than those recorded in pure air conditions, suggesting that the product possesses characteristics of p-type semiconductors.

\section{Gas sensing mechanism}

It is well accepted that the sensor response of the semiconductor gas sensors is attributed to the chemisorption of oxygen molecules on the oxide surface and the subsequent reaction between the adsorbed oxygen species and tested gas, which causes the resistance variation. ${ }^{43,44}$ The same mechanism has been used to explain the formaldehyde sensing characteristics of the present $\mathrm{NiO}$ sensors, which may be described as follows (Fig. 10).

As p-type semiconductor, NiO vacancies occur in cation sites, which act as electron donors while oxygen molecules act as acceptors. Initially, in air, oxygen molecules are adsorbed on the surface of the NiO sensors and electrons are consumed following the reactions: $:^{25,45}$ 

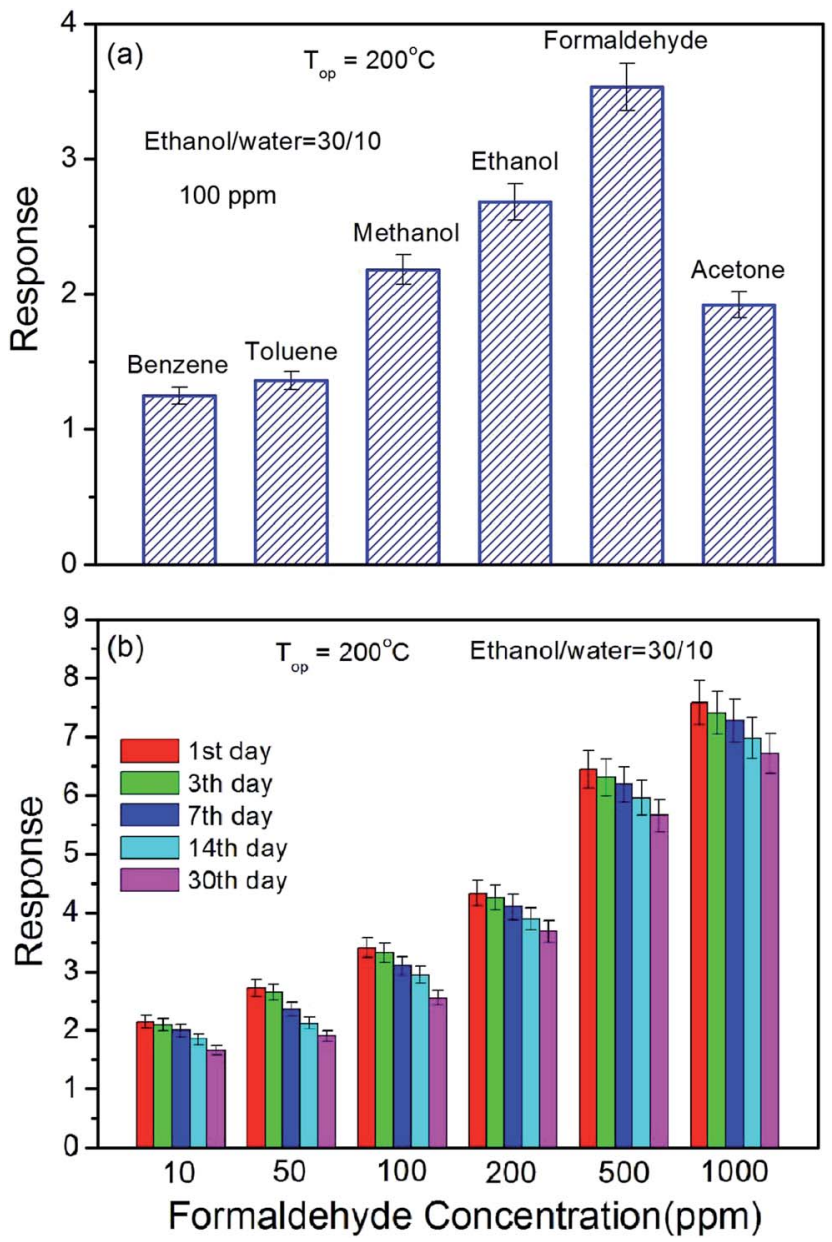

Fig. 8 (a) Selectivity and (b) stability of the sensor made of the annealed product synthesized at ethanol/water volume ratio of $30 / 10$.

$$
\begin{gathered}
\mathrm{O}_{2} \text { (gas) } \rightarrow \mathrm{O}_{2} \text { (ads) } \\
\mathrm{O}_{2} \text { (ads) }+\mathrm{e}^{-} \rightarrow \mathrm{O}_{2}{ }^{-} \text {(ads) } \\
\mathrm{O}_{2}{ }^{-} \text {(ads) }+\mathrm{e}^{-} \rightarrow 2 \mathrm{O}^{-} \text {(ads) } \\
\mathrm{O}^{-} \text {(ads) }+\mathrm{e}^{-} \rightarrow \mathrm{O}^{2-} \text { (ads) }
\end{gathered}
$$

Thus, these charged oxygen species causes an increase in the electrical holes inside the NiO sensing film, and thus decrease its resistance. With the temperature increase, the surface reaction is thermally activated, causing a largely decrease in resistance. Flower-like structures assembled with nanosheets owing a large surface area and high porosity are favorable to the adsorption of oxygen molecules, resulting in the lower resistance compared to microsheets/nanosheets. On the other hand, the electrical holes are thermally excited at high temperature, also resulting in the decrease in resistance with increasing temperature. While as the temperature further increases, oxygen desorption rapidly increases and the thermally holes become to equilibrium, these cause the slow change in resistance at high temperature. ${ }^{27,46}$ Therefore, the resistance decreases rapidly at temperatures below $200{ }^{\circ} \mathrm{C}$, and then change to be steady at high temperature, as shown in Fig. 9.
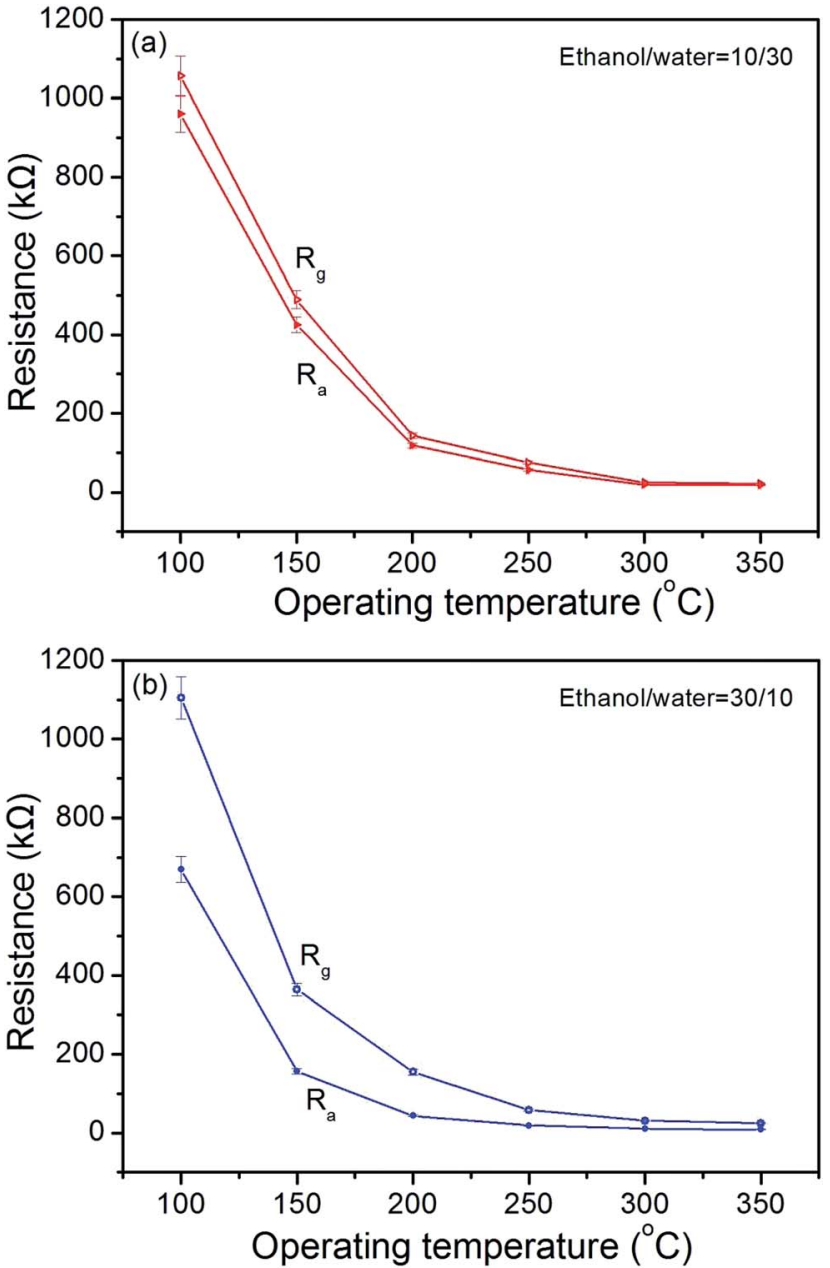

Fig. 9 The temperature dependences of the resistances in air and in air including formaldehyde gas: (a) ethanol/water $=10 / 30$ (microsheets/nanosheets), and (b) ethanol/water $=30 / 10$ (flower-like structures).

When the sensors are exposed to formaldehyde, these gaseous molecules will adsorb and react with these chemisorbed oxygen species, following relations: ${ }^{47}$

$$
\mathrm{HCHO}(\text { gas })+\mathrm{O}_{2}^{-} \text {(ads) } \rightarrow \mathrm{CO}_{2}+\mathrm{H}_{2} \mathrm{O}+\mathrm{e}^{-}
$$

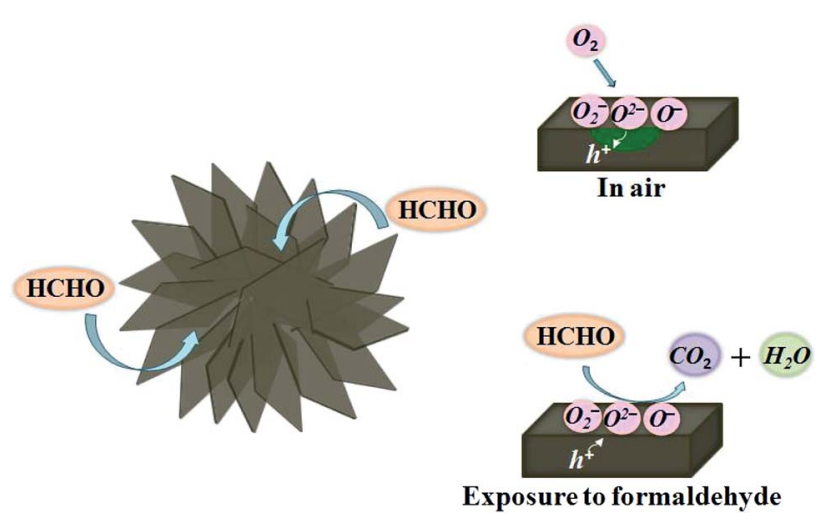

Fig. 10 Schematic illustration of formaldehyde sensing mechanism. 


$$
\begin{aligned}
& \mathrm{HCHO}(\text { gas })+2 \mathrm{O}^{-} \text {(ads) } \rightarrow \mathrm{CO}_{2}+\mathrm{H}_{2} \mathrm{O}+2 \mathrm{e}^{-} \\
& \mathrm{HCHO}(\text { gas })+2 \mathrm{O}^{2-}(\text { ads }) \rightarrow \mathrm{CO}_{2}+\mathrm{H}_{2} \mathrm{O}+4 \mathrm{e}^{-}
\end{aligned}
$$

This process releases the electrons back to NiO, which induces a decrease of the hole concentration by electron-hole recombination, leading to an increase in the resistance. The hierarchical structures with a large surface area and high porosity offer abundant active sites for chemisorptions and reactions of formaldehyde gas, and provide an effective gas diffusion path via well-aligned porous architectures. Therefore, the flower-like NiO hierarchical architectures exhibit excellent sensing properties. The increase in response with increasing formaldehyde concentration is attributed to the higher surface coverage of the sensor with formaldehyde molecules, which enhances the sensing response.

\section{Conclusions}

Flower-like NiO hierarchical architectures were synthesized by solvothermal process without using any other surfactant. The structure characteristics and formaldehyde sensing properties of NiO structures were investigated. The flower-like NiO hierarchical architectures were identified as cubic crystal structure, which were constructed by a number of thin nanosheets with a thickness of about $30 \mathrm{~nm}$. The sensor made of well-defined $\mathrm{NiO}$ flower-like structures with large special surface area showed the higher response at $200{ }^{\circ} \mathrm{C}$. Moreover, the reversible and fast response to formaldehyde gas at various gas concentrations and good selectivity and stability were obtained. These results suggested that well-defined NiO flower-like structures have excellent potential application for fabrication high performance sensors.

\section{Acknowledgements}

The authors are grateful for the support of the National Natural Science Foundation of China (no. 21503137, 61403263, 61374017, 51422402 and 51301114), Scientific Research Foundation for the Returned Overseas Chinese Scholars, State Education Ministry (no. 20141685), and Liaoning Educational Department Foundation (no. L2015425 and L2014167).

\section{References}

1 G. Hodes, Adv. Mater., 2007, 19, 639-655.

2 N. P. Zaretskiy, L. I. Menshikov and A. A. Vasiliev, Sens. Actuators, B, 2012, 170, 148-157.

3 T. J. Liu, Q. Wang and P. Jiang, RSC Adv., 2013, 3, 1266212670.

4 F. T. Li, J. Ran, M. Jaroniecc and S. Z. Qiao, Nanoscale, 2015, 7, 17590-17610.

5 J. Xu, Y. S. Yu, X. X. He, J. B. Sun, F. M. Liu and G. Y. Lu, Mater. Lett., 2012, 81, 145-147.

6 V. Polshettiwar, B. Baruwati and R. S. Varma, ACS Nano, 2009, 3, 728-736.
7 H. Y. Chen, D. B. Kuang and C. Y. Su, J. Mater. Chem., 2012, 22, 15475-15489.

8 J. H. Lee, Sens. Actuators, B, 2009, 140, 319-336.

9 S. H. Ko, D. Lee, H. W. Kang, K. H. Nam, J. Y. Yeo, S. J. Hong, C. P. Grigoropoulos and H. J. Sung, Nano Lett., 2011, 11, 666671.

10 J. R. Huang, X. J. Xu, C. P. Gu, M. Yang, M. Yang and J. H. Liu, J. Mater. Chem., 2011, 21, 13283-13289.

11 J. Y. Wang, N. L. Yang, H. J. Tang, Z. H. Dong, Q. Jin, M. Yang, D. Kisailus, H. J. Zhao, Z. Y. Tang and D. Wang, Angew. Chem., 2013, 125, 6545-6548.

12 Y. Wang and Q. S. Zhu, Mater. Res. Bull., 2010, 45, 1844-1849. 13 L. L. Yang, Q. F. Han, J. Zhao, J. W. Zhu, X. Wang and W. H. Ma, J. Alloys Compd., 2014, 614, 353-359.

14 D. Meng, G. S. Wang, X. G. San, Y. M. Song, Y. B. Shen, Y. J. Zhang, K. J. Wang and F. L. Meng, J. Alloys Compd., 2015, 649, 731-738.

15 Z. Skoufa, E. Heracleous and A. A. Lemonidou, J. Catal., 2015, 322, 118-129.

16 Y. Z. Zheng, H. Y. Ding and M. I. Zhang, Mater. Res. Bull., 2009, 44, 403-407.

17 L. H. Chu, M. C. Li, X. D. Li, Y. Wang, Z. P. Wan, S. Y. Dou, D. D. Song, Y. F. Li and B. Jiang, RSC Adv., 2015, 5, 4976549770.

18 S. Lv, C. G. Wang and S. X. Xing, J. Alloys Compd., 2014, 603, 190-196.

19 W. Wen, J. M. Wu and M. H. Cao, J. Mater. Chem. A, 2013, 1, 3881-3885.

20 Y. Q. Zou and Y. Wang, Nanoscale, 2011, 3, 2615-2620.

21 X. Xu, J. Liang, H. Zhou, S. J. Ding and D. M. Yu, RSC Adv., 2014, 4, 3181-3187.

22 X. Xu, H. Tan, K. Xi, S. J. Ding, D. M. Yu, S. D. Cheng, G. Yang, X. Y. Peng, A. Fakeeh and R. V. Kumar, Carbon, 2015, 84, 491-499.

23 H. J. Kim and J. H. Lee, Sens. Actuators, B, 2014, 192, 607-627.

24 X. G. San, G. H. Wang, B. Liang, J. Ma, D. Meng and Y. B. Shen, J. Alloys Compd., 2015, 636, 357-362.

25 C. Luyo, R. Ionescu, L. F. Reyes, Z. Topalian, W. Estrada, E. Llobet, C. G. Granqvist and P. Heszler, Sens. Actuators, $B, 2009,138,14-20$.

26 B. Liu, H. Q. Yang, H. Zhao, L. J. An, L. H. Zhang, R. Y. Shi, L. Wang, L. Bao and Y. Chen, Sens. Actuators, B, 2011, 156, 251-262.

27 C. J. Dong, X. C. Xiao, G. Chen, H. T. Guan, Y. D. Wang and I. Djerdj, RSC Adv., 2015, 5, 4880-4885.

28 L. P. Gao, F. M. Ren, Z. X. Cheng, Y. Zhang, Q. Xiang and J. Q. Xu, CrystEngComm, 2015, 17, 3268-3276.

29 Z. Y. Wang, X. Zhou, Z. B. Li, Y. C. Zhuo, Y. Gao, Q. Y. Yang, X. W. Lia and G. Y. Lu, RSC Adv., 2014, 4, 23281-23286.

30 F. L. Meng, N. N. Hou, S. Ge, B. Sun, Z. Jin, W. Shen, L. T. Kong, Z. Guo, Y. F. Sun, H. Wu, C. Wang and M. Q. Li, J. Alloys Compd., 2015, 626, 124-130.

31 T. M. Li, W. Zeng, H. W. Long and Z. C. Wang, Sens. Actuators, B, 2016, 231, 120-128.

32 K. Tian, X. X. Wang, H. Y. Li, R. Nadimicherla and X. Guo, Sens. Actuators, B, 2016, 227, 554-560. 
33 X. W. Li, S. L. Xiong, J. F. Li, J. Bai and Y. T. Qian, J. Mater. Chem., 2012, 22, 14276-14283.

34 L. P. Xu, Y. L. Hu, C. Pelligra, C. H. Chen, L. Jin, H. Huang, S. Sithambaram, M. Aindow, R. Joesten and S. L. Suib, Chem. Mater., 2009, 21, 2875-2885.

35 S. Das, S. Chaudhuri and S. Maji, J. Phys. Chem. C, 2008, 112, 6213-6219.

36 H. M. Du, L. F. Jiao, K. Z. Cao, Y. J. Wang and H. T. Yuan, ACS Appl. Mater. Interfaces, 2013, 5, 6643-6648.

37 Y. Y. Yang, Y. R. Liang, Z. Y. Zhang, Y. D. Zhang, H. Y. Wu and Z. G. Hu, J. Alloys Compd., 2016, 658, 621-628.

38 Y. Zhou, C. Liu, X. Zhong, H. Y. Wu, M. Y. Li and L. P. Wang, Ceram. Int., 2014, 40, 10415-10421.

39 D. Han, P. Song, H. H. Zhang, H. H. Yan, Q. Xu, Z. X. Yang and Q. Wang, RSC Adv., 2014, 4, 50241-50248.
40 H. Chen, Q. W. Wang, C. L. Kou, Y. M. Sui, Y. Zeng and F. Du, Sens. Actuators, B, 2014, 194, 447-453.

41 W. W. Guo, T. M. Liu, H. J. Zhang, R. Sun, Y. Chen, W. Zeng and Z. C. Wang, Sens. Actuators, B, 2012, 166-167, 492-499.

42 S. H. Wei, S. M. Wang, Y. Zhang and M. H. Zhou, Sens. Actuators, B, 2014, 192, 480-487.

43 N. Yamazoe, G. Sakai and K. Shimanoe, Catal. Surv. Asia, 2003, 7, 63-75.

44 D. Meng, T. Yamazaki and T. Kikuta, Sens. Actuators, B, 2014, 190, 838-843.

45 R. Y. Miao, W. Zeng and Q. Gao, Appl. Surf. Sci., 2016, 384, 304-310.

46 A. Hakim, J. Hossain and K. A. Khan, Renewable Energy, 2009, 34, 2625-2629.

47 C. J. Dong, Q. Li, G. Chen, X. C. Xiao and Y. D. Wang, Sens. Actuators, B, 2015, 220, 171-179. 